\title{
Primary and Secondary Teachers' Knowledge, Interpretation, and Approaches to Students Errors about Ratio and Proportion Topics
}

\author{
Elena Fabiola Ruiz Ledesma \\ Graduate Department, School of Computer Sciences of the National Polytechnical Institute of Mexico, \\ Gustavo A. Madero, Mexico. \\ Email: efruiz@ipn.mx \\ Received July 15 $5^{\text {th }}, 2011$; revised July 29 $9^{\text {th }}, 2011$; accepted August $2^{\text {nd }}, 2011$.
}

\begin{abstract}
This study investigated elementary and secondary teachers' understanding and pedagogical strategies applied to students making errors in finding a missing length in similar rectangles. It was revealed that secondary teachers had better understanding of ratio and proportion in similar rectangles than elementary teachers. While all secondary teachers solved the similar rectangles problems correctly, a large portion of elementary teacher struggled with the problem. In explaining their solution strategies, and even though similar strategies appeared both from elementary teachers and secondary teachers, a majority of secondary teachers pointed out the underlying idea of similarity, whereas less than half of the elementary teachers explained their reasoning for using ratios and proportion. This article is derived from the research project registered under number 20110343 (Ruiz, 2011), and developed in Escuela Superior de Cómputo del Instituto Politécnico Nacional (IPN) (School of Computer Sciences of the National Poly-technical Institute of Mexico)
\end{abstract}

Keywords: Primary Teachers, Secondary Teachers, Knowledge, Ratio, Proportion' Problems

\section{Introduction}

The development of proportional thinking is important since basic educational levels, as from it depend that children can be able to comprehend and face everyday situations which are linked with the proportion concept. At the same time, as it is established by Ruiz and Lupiañez, (2009) so the student of basic level can give sense and meaning to the proportion concept it is very important to develop their proportional thinking such as the qualitative as the quantitative. That is to say, for the development of proportional thinking it is required, among others that the subject can build the concept of proportion.

The NCTM document (2000) describes proportionality to be "of such great importance that it merits whatever time and effort that must be expended to assure its careful development" (p. 82 ). Very often multiplication and division tasks in the lower grades are presented in unit-rate form, which is a special form of ratio and proportion. In the middle grades, word problems involving equivalent fractions and fraction comparisons can also be thought of as ratio and proportion situations (NCTM, 2000). The ability to recognize structural similarity and multiplicative comparisons illustrated in such proportional reasoning processes are the cornerstone of algebra and more advanced mathematics (Kilpatrick, Swafford, \& Findell, 2001). Nevertheless, research has consistently shown that many students have difficulty with developing proportional reasoning. Hart (1984), for example, reported that less than $42 \%$ of students in grade 7 succeeded in solving simple problems of enlargement, a most common error is additive reasoning (Lamon, 2007). According to these studies, students tend to focus on the difference between the given quantities rather than proportionality illustrated in given contexts.

\section{The Problem and the Research Questions}

In this study I set out to investigate elementary and secondary teachers' reasoning, their responses to student errors on the topic of ratio and proportion, and the relationship between their knowledge and approaches. I used aforementioned student error in exploring teachers' reasoning and approaches. I was curious about how teachers would interpret and respond to student errors in finding a missing length in similar rectangles, and how their approaches related to their mathematical knowledge. Although a growing body of research has focused on teachers' treatment of student errors (e.g., Schleppenbach, Flevares, Sims, \& Perry, 2007; Ruiz, 1997; Ruiz, 2002), teach-ers' responses and their strategies have received limited attention in the research literature. If teachers are called to use student errors as springboards for inquiry into mathematical concepts, it is important to explore teachers' responses and strategies to student errors, and prepare them to make better use of student errors through teacher education programs.

\section{The Purpose}

The purpose of this study is not to add to the collection of studies documenting teacher weakness, but rather to inform the design of teacher education in this area. Exploration of teachers' interpretations of and responses to student ideas and, in particular, student errors will help enrich a dialogue among reformers, educators, and professional developers in ways they could help teachers learn to teach math to promote student understanding. More specifically, the research questions guiding the study included: 
- What instructional support do teachers need to provide?

- How do teachers need to use student errors in instruction?

\section{Background}

\section{Teacher Knowledge, Approaches and Its Relationship}

Although many researchers have devoted considerable attention over the last two decades to what teachers should know and be able to do, there are still large gaps in this research, in particular, research studies on teachers' knowledge of ratio and proportion. Fisher (1998), for example, investigated secondary mathematics teachers' understanding and strategy usage in ratio and proportion problems. He used word problems involving direct proportional reasoning and inverse proportional reasoning. He reported that, overall, teachers were more successful with direct proportional reasoning problems (i.e., $y=k x$ ) than with inverse proportional problems (i.e., $x y=k$ ). However, the strategy chosen by teachers varied with the type of problem. In terms of teaching approaches, he reported that most teachers said they would use the same strategies they used while teaching the problems tested. Lim (2009) investigated twenty-eight preservice teachers with four types of invariance in miss-value problems: ratio, sum, product, and difference. He found that preservice teachers had different levels of understanding depending on the type of problems. While teachers had less difficulty with the first and second problems (ratio and sum), they showed greater difficulty with a missing value task involving product and difference. Ruiz, 1997, 2000 and 2002, reported that teachers generally do not pay close attention to the meaning of ratios when they set up a proportion to solve a missing value problem, indicating that teachers tend to use the same approach for a missing value problem regardless of different contexts. Although the findings from these studies help us understand teachers' understanding and strategies, there remains a need for research to unfold how the teachers' own understandings impact their interpretations of the students' misconceptions. An investigation of this important topic is described here.

\section{Strategies in Ratio and Proportion problems}

In analyzing teachers' knowledge, interpretation, and approaches to student error(s), I was guided by the studies of Ruiz, 2000 , and 2002, who distinguished between the use of procedural and conceptual knowledge. I also referred to the studies of Fisher (1999) and Lamon (2007), who articulated different levels of understanding of ratio and proportion. Ruiz defined conceptual knowledge as explicit or implicit understanding of the principles that govern a domain and of the interrelations between pieces of knowledge in a domain. They defined procedural knowledge as action sequences for solving problems. These two types of knowledge lie on a continuum and cannot always be separated; however, the two ends of the continuum represent two different types of knowledge. More detailed examples will follow of these two forms of knowledge regarding ratio and proportion in similar rectangles as I discuss the findings of the study.

\section{Methodology}

This study investigated teachers' interpretation of and re- sponses to student error(s) through a classroom scenario in which an imaginary student incorrectly solved a similar rectangles problem. The study also examined how teachers' pedagogical strategies used to address the student errors are related to their content knowledge of ratio and proportion.

One task (content knowledge and pedagogical content knowledge) was developed based on Ruiz, (2002). The content knowledge task was aimed at assessing teachers' understanding of ratio and proportion. The first question, called similar rectangles problem, required teachers to find the missing side of a rectangle given the condition the two rectangles are similar, and to explain their solution. The pedagogical content knowledge followed the content knowledge task. After completing the similar rectangles problem, they were asked to interpret and respond to a student's incorrect solution. According to Ruiz, 2000, 2002, and Ruiz and Lupiañez, 2009, the most common incorrect strategy in finding the length of the missing side in similar rectangle is to use additive reasoning $(\mathrm{A}-\mathrm{B}=\mathrm{C}-\mathrm{B})$ focusing on the difference between the given length in similar rectangles, rather than focusing on proportional relationship between two figures $(\mathrm{A} / \mathrm{B}=\mathrm{C} / \mathrm{D})$. I based my exploration of teachers' pedagogical content knowledge (PCK) on this common incorrect strategy. The teachers were asked to identify one fictitious student's (Lilith) error(s) and then to provide a written description of how they would respond to her (see Figure 1).

\section{Sample}

Fifty-seven teachers participated in this study. Thirty-one were of the elementary school and twenty six were of secondary school in Mexico City.

\section{Task}

The tasks went through multiple phases of revisions and were pilot tested with two volunteers who were then interviewed to check for possible misunderstandings. The final version of the task was then administered as an in-class survey in three mathematics methods course sections, two elementary and the other secondary, towards the end of the semester. This study only includes data from teachers who signed the study's consent form. For data analysis, responses to the content knowledge task were first identified based on correctness and then solution strategies were identified. The final phase of analysis consisted of the identification of emergent patterns in teaching strategies.

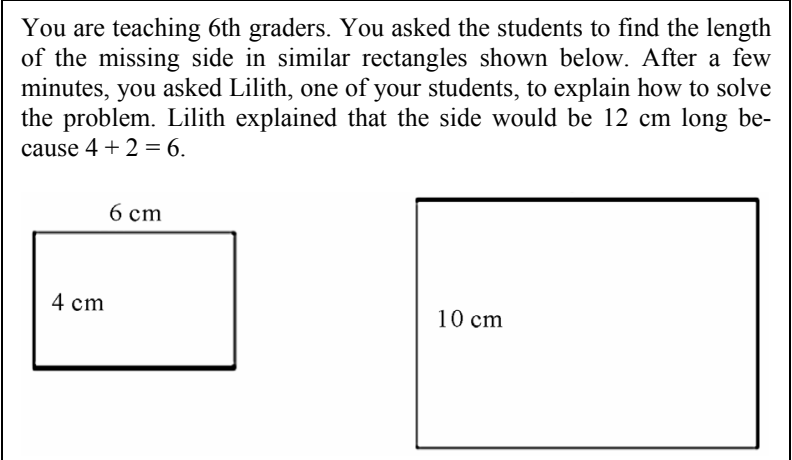

Figure 1.

Contains the problem. Ruiz, 2002. 


\section{Summary of Results}

\section{How Do Teachers Understand Ratio and Proportion?}

The findings from the content knowledge task were helpful in providing an initial framework for analyzing the PCK task. In the first problem, teachers were asked to find a missing length in similar rectangles where a rectangle that began as a 4 $\mathrm{cm}$ by $6 \mathrm{~cm}$ was enlarged to a rectangle with a short side of 10 $\mathrm{cm}$. All secondary teachers answered correctly and $73 \%$ of elementary teachers (22 out of 31 ) answered correctly. Among the teachers who provided incorrect answers, 6 teachers used a common strategy, additive reasoning, by focusing on the difrences between the given quantities. One typical response was as follows:

Teacher 1. "I think that the missing side is $12 \mathrm{~cm}$ because the difference between $4 \mathrm{~cm}$ and $6 \mathrm{~cm}$ is 2 therefore the difference between the 2 sides of the larger rectangle would also be 2.10 $\mathrm{cm}+2=12 \mathrm{~cm}$ ".

Among teachers who provided correct answers, three different solution approaches were used-within ratios, between ratios, and unit-rate (or scale factors) as addressed in Table 1.

Table 2 shows the frequency of each type of solution strategies by teachers. While the most frequently used strategy is the within ratio approach among elementary teachers, the between ratio approach is used most often in secondary teachers.

I was also curious to know if teachers pointed out the lying idea of similarity of rectangles, the concept of similarity, when explaining their solution approaches because finding a missing length in similar rectangles involves not only understanding the concept of similarity but also procedural knowledge of setting up a proportion and performing calculations.

Among elementary teachers who provided correct solution strategies, $48 \%$ of elementary teachers (11 out of 23 ) referred to the concept of similarity while $81 \%$ of secondary teachers $(21$ out of 26) pointed out the property of similarity of figure. This indicates that a smaller percentage of secondary teachers carried out three methods as a rote procedure that requires little proportional reasoning.

\section{How Do Teachers Identify Lilith's Learning Difficulties?}

In a classroom setting, our student, Lilith was asked to solve the same problem teachers completed--find a missing length in similar rectangles. Lilith concluded that the long side is $12 \mathrm{~cm}$ since $4 \mathrm{~cm}+2 \mathrm{~cm}=6 \mathrm{~cm}$. As I addressed earlier, finding a missing length in similar rectangles involves at least four big ideas: 1) understanding the concept of similarity, 2) determineing a between ratio, within ratios, or a scale factor, 3) setting up a proportion, and 4) carrying out calculations correctly. In Lilith's case, she did not understand the concept of similarity-the lengths of the corresponding sides in similar rectangles increase (or decrease) by a constant ratio. As such, she focused on the difference, in particular, within difference, by comparing the difference between the length and the width within a rectangle. Although she carried out the calculation correctly based on additive reasoning, she was not able to find the correct missing length in similar rectangles. The fundamental error in Lilith's case results from not understanding the concept of similarity.

In analyzing the responses of the teacher participants, three categories of interpretation were identified and are illustrated below. The first interpretation was to classify different ways of identifying Lilith's learning difficulties using a conceptual approach - in this case, focusing on the meaning of similarity of rectangles, in which the following hold: two figures are similar if 1) the measures of their corresponding angles are equal, 2) the lengths of their corresponding sides increase (or decrease) by the same factor, called the scale factor, and 3) the perimeter from one rectangle to another rectangle also increases by the same scale factor. The conceptual approaches also included the idea of enlargement or reduction in similar rectangles. I call this type of identification of Lilith's error as similarity-based. One typical response was as follows:

Lilith does not understand that similar means proportion or she may not understand what proportional means.

Table 1.

Example of different methods used by teachers.

\begin{tabular}{|c|c|c|}
\hline Between Ratios & Within Ratios & Scale factor method \\
\hline$\frac{4}{10}=\frac{6}{x}$ & $\frac{6}{4}=\frac{x}{10}$ & $\begin{array}{l}\text { Ratio of smaller to bigger similar rectangle is } 4 \text { : } \\
10 \text {. }\end{array}$ \\
\hline $\begin{array}{l}\text { If the rectangles are similar, their sides are at a } \\
\text { constant ratio. Thus you can compare the ratio } \\
\text { between the width and length and use this propor- } \\
\text { tion to find missing length from the width of same } \\
\text { rectangle. } x 6104=\end{array}$ & $\begin{array}{l}\text { Assuming the } 4 \mathrm{~cm} \text { side is similar to the } 10 \mathrm{~cm} \\
\text { side I must find a relationship between } 6 \mathrm{~cm} \\
\text { and } x \text {. I create a fraction with } 6 \mathrm{~cm} \text { and } 4 \mathrm{~cm} \text { and } \\
\text { set it equal to } \mathrm{x} \text { and } 10 \mathrm{~cm} \text {. Cross multiply and } \\
\text { solve for } \mathrm{x}\end{array}$ & $6 \times \frac{10}{4}, 6 \times 2 \frac{1}{2},=12+3=15$ \\
\hline
\end{tabular}

Table 2.

Solution Strategy used in finding a missing length by teachers.

\begin{tabular}{ccccc}
\hline & Category & Elem. $(\mathrm{N}=31)$ & Second. $(\mathrm{N}=26)$ & Total $(\mathrm{N}=57)$ \\
\hline \multirow{2}{*}{ Incorrect } & Additive & $7(22 \%)$ & $0(0 \%)$ & $7(12 \%)$ \\
Correct & Within ratio & $14(45 \%)$ & $7(27 \%)$ & $21(36 \%)$ \\
& Between ratio & $8(25 \%)$ & $15(58 \%)$ & $23(40 \%)$ \\
& Scale factor methods & $3(1 \%)$ & $4(15 \%)$ & $7(12 \%)$ \\
\hline
\end{tabular}


A proportion is a ratio of two numbers, where Lilith looked at the sum (or difference, depending on how you think about it) of sides.

The procedural approach involves finding the missing value in a proportion, which relates to big ideas 2 through 4 outlined above (i.e., determining ratios, setting up a proportion, and carrying out the calculation). In this approach, teachers also indicated the need for a ratio, proportion, or a scale factor for calculation. This type of identification of Lilith's error is called procedure-based.

Lilith did not calculate the ratio of corresponding sides, i.e., 4 $\mathrm{cm} / 10 \mathrm{~cm}=$ ratio of sides. What Lilith did was $6-4=2 \mathrm{~cm}$ difference then added $10 \mathrm{~cm}+2 \mathrm{~cm}=12 \mathrm{~cm}$.

In addition to these two categories of interpretation, a third category involved responses indicating misdiagnosis of Lilith's error based either on additive reasoning or incorrect focus. In most cases of additive reasoning, teachers indicated Lilith's errors stemmed from not comparing the difference between rectangles. The following are examples:

Lilith is explaining the relationship between the sides 4 and 6 rather than first comparing sides 4 and 10 then 6 and $\mathrm{x}$. So she should be looking at how side 4 is related to side 10 , then use that same relation with side 6 to get side $\mathrm{x}$.

Table 3 shows subcategories of each approach and the distribution of response in terms of similarity-oriented vs. procedural-oriented.

Four subcategories were devised with respect to the similarity-oriented approach. While teachers in category one did not provide a definition of similarity, teachers in category two stated specifically that Lilith did not see the relationship between two similar rectangles as a constant ratio. Although teachers in category three and four stated Lilith's limited understanding of the concept of similarity, teachers in category three pointed out specifically that Lilith's errors came from not comparing the lengths between the two rectangles. In the case of category four, teachers indicated Lilith's difficulty as not visualizing enlargement of the second rectangle. In terms of the procedural approaches, four subcategories were devised as well. The major difference between the conceptual vs. procedural approach lies in the focus of indication of Lilith's errors. Interestingly, when teachers were asked to identify Lilith's errors, they tended to rephrase Lilith's method by pointing out the use of difference in calculation, which is coded into the first category in the procedural approach. Table 3 shows that, although Lilith's errors came from her limited understanding of similarity rather than from procedural knowledge of setting up an equation, teachers in this study tended to identify her errors more from a procedural perspective.

\section{How Do Teachers Respond to Lilith's Work?}

I performed the same analysis on the responses the teachers provided for the question asking them to describe how they would respond to Lilith. Table 3 shows the distribution of response in terms of concept-oriented vs. procedure-oriented.

Table 4 shows that more than half of the teachers provided guidance from procedural aspects of similarity. I was intrigued

Table 3.

Teachers' Identification of Lilith's error.

\begin{tabular}{cccc}
\hline Type of Identification & Subcategory & \# of response & Total \\
\hline \multirow{3}{*}{ Similarity-based } & Meaning of similarity & 2 & $19(34 \%)$ \\
& Recognizing the similarity by a constant ratio & $12^{*}$ & 3 \\
& Comparing lengths between rectangles & 2 & $30(53 \%)$ \\
Visualization of enlargement in similar figures & 11 & $13^{*}$ \\
Procedure-based & Use of addition or difference in calculation & 3 & $8(13 \%)$ \\
& Use of a ratio or proportion in calculation & 3 & 57 \\
Misdiagnosed & Comparing lengths between figures in calculation & 8 & 57 \\
Total & Additive reasoning or incorrect identification & & 57 \\
\hline
\end{tabular}

Table 4.

Type of strategy employed by Lilith.

\begin{tabular}{cccc}
\hline Type of Strategy & Subcategory & \# of response & Total \\
\hline \multirow{3}{*}{ Similarity-based } & Recognizing the similarity by a constant ratio & 2 & $21(37 \%)$ \\
& Comparing lengths between figures & 2 & \\
& Idea of enlargement in similar figures & $10^{*}$ & $33(58 \%)$ \\
Procedure-based & Finding a ratio proportion in calculation & $22^{*}$ & 3 \\
Scaling up by a scale factor in calculation & 8 & $3(5 \%)$ \\
Misdiagnosed & Comparing lengths within a figure in finding a proportion & 57 & 57 \\
\hline
\end{tabular}

Note: * represents the most frequently referred category. 
to find out how the teachers who recognized Lilith's error in terms of conceptual aspects of similarity would respond to Lilith. A comparison of Tables 3 and 4 shows that although the frequency of focusing on the meaning of similarity slightly increased from identifying the learning difficulties and responding to it, teachers tended to provide their intervention based on the procedural aspects of similarity.

In addition to this approach, I explored two forms of approaches addressed by teachers to student errors-teacherfocused vs. student-focused. While $81 \%$ of the secondary teachers provided teacher-directed approaches of telling and explaining, less than half of the elementary teachers used a student-focused approach by engaging Lilith in activities or questions. Furthermore, I also observed teachers' using the three different approaches to student errors identified by Ruiz and Lupiañez (2009) in their examination of teachers' pedagogical strategies to student errors in reflective symmetry: 1) Generalization, 2) Return to the basics, and 3) A Plato-andthe-slave-boy approach.

Now I present an analysis of two tasks Lilith answered incorrectly: task 1 and task 2 .

In task 1, the drawing of a house was presented and the student was required to select the correct reduced sketching of the original drawing (see Figure 2). Lilith selected a sketching that did not correspond to the original drawing and she argued that her choice resembled best the original drawing of a house. I observed that she almost did not use her common sense or visualization.

About the task 2, the text is: Mr. Escalante has been asked to make an amplification of the following original drawing (see Figure 3). To the right, you can see a portion of the amplified drawing. Complete that amplification keeping the form of the original draw.

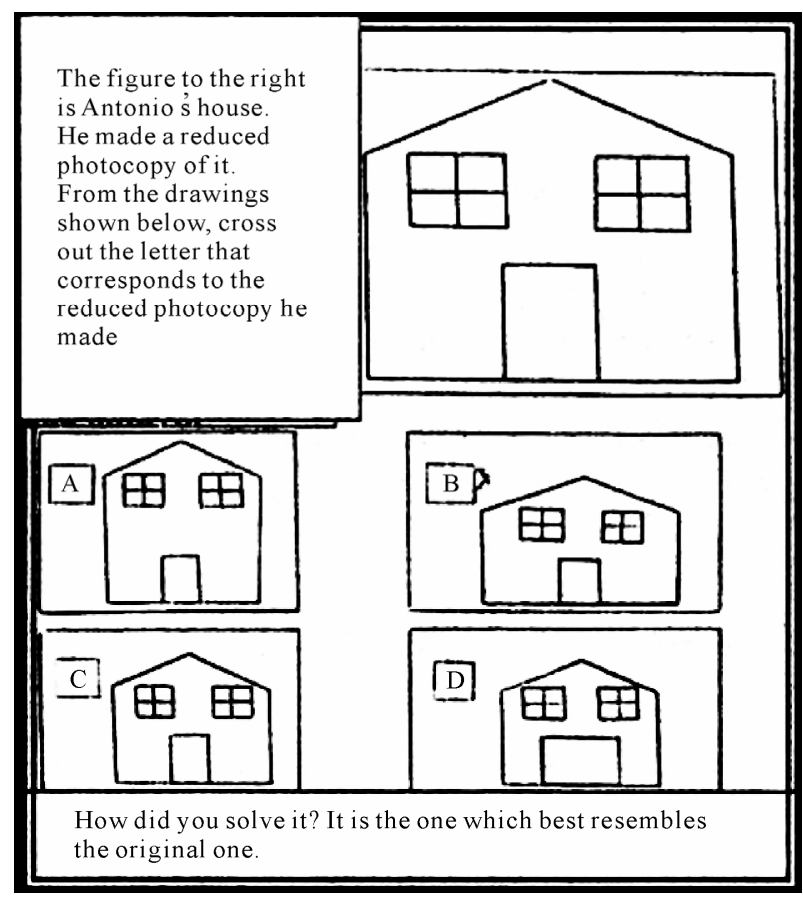

Figure 2.

Contains the problem. Ruiz, 2002.
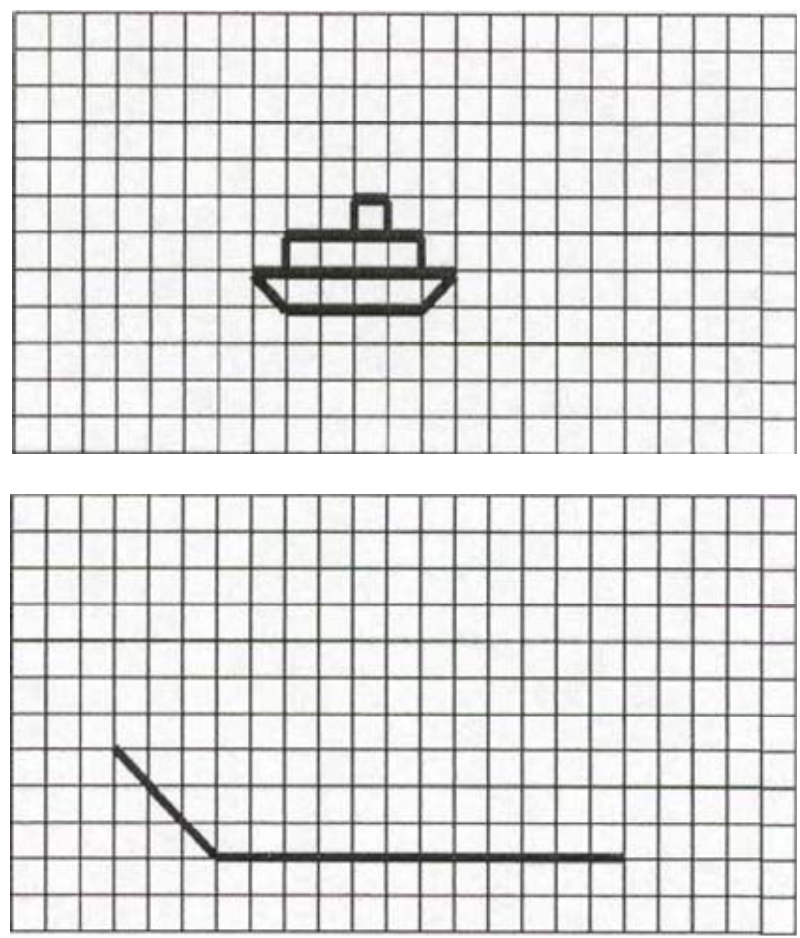

Figure 3.

Task 2. Ruiz, 2002.

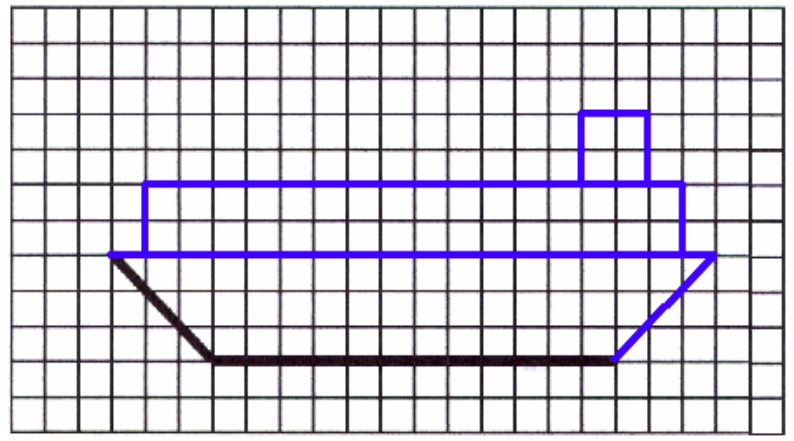

Figure 4.

Task 2 solved by Lilith. Ruiz, 2002.

As shown in Figure 4, Lilith completed the drawing but she did not notice that she had amplified it twice and not thrice.

I worked with those notions by referring to concrete situations of the type of the experience of reproducing a drawing to scale and of the idea of using a photocopier.

I would like to mention that Lilith was representative of those students who had a lot of recourse to handling algorithms that made no sense and who simultaneously exhibited few elaborations in the qualitative context.

\section{Conclusion}

This study showed that, although a student's error stemmed from lack of understanding of the concept of similarity, a majority of elementary and secondary teachers identified the stu- 
dent's errors from a procedural perspective of similarity. When they responded to the student's errors, they guided the student by invoking procedural knowledge.

Another interesting finding was that, although secondary teachers showed better understanding of the mathematical concepts presented in this study than elementary teachers when responding to student errors, secondary teachers tended to rely on a teacher-focused approach of telling or explaining students' errors whereas elementary teachers tended to use a studentocused approach by asking questions or providing related activities to help students overcome conceptual misunderstanding. These results are consistent with the findings reported by Ruiz, 1997.

\section{References}

Fisher, L. (1998). Strategies used by secondary mathematics teachers to solve proportion problems. Journal for Research in Mathematics Education, 19, 157-168. doi:10.2307/749409

Hart, K. (1984). Ratio: Children's strategies and errors. Windsor, England: NFER-Nelson.

Kilpatrick, J., Swafford, J., \& Findell, B. (Eds.). (2001). Adding it up: Helping children learn mathematics. Washington D.C.: The National Academies Press.

Lamon, S. J. (2007). Rational numbers and proportional reasoning: Toward a theoretical framework. In F. Lester (Ed.), Second handbook of research on mathematics teaching and learning (pp. 629-668). Charlotte, NC: Information Age Publishing.
Lim, K. H. (2009). Burning the candle at just one end: Using nonproportional examples helps students determine when proportional strategies apply. Mathematics Teaching in the Middle School, 14, 492-500.

NCTM (2000). Principles and standards for school mathematics. Reston, VA: National Council of Teachers of Mathematics.

Ruiz, E. F. (2011) Indicadores teóricos para la Constricción de conceptos del cálculo diferencial. Proyecto de investigación registrado en la Secretaría de Investigación y Posgrado (SIP), del IPN con núm. de registro CGPI 20110343. México. IPN,

Ruiz, E. F. (1997). Uso de las calculadoras math explorer y ti-92 en la resolución de problemas: Una experiencia con profesores de los niveles básico y medio. Memorias del Seminario Nacional de Calculadoras y Computadoras en Educación Matemática, 25-35.

Ruiz, E. F. (2000) Study of solving strategies and proposal for the teaching of ratio and proportion. Proceedings of the Twenty-Second Annual Meeting North American Chapter of the International Group For The Psychology of Mathematics Education, 2, 395-396.

Ruiz, E. F. (2002). Estudio de estrategias de solución y una propuesta de enseñanza de razón y proporción. Tesis Doctoral. Cinvestav-IPN. México. 17-344.

Ruiz, E. F., \& Lupiañez, J. L. (2009). Detección de obstáculos psicopedagógicos en la enseñanza y el aprendizaje de los tópicos de razón y proporción en alumnos de sexto grado de educación primaria. Revista Electrónica de Investigación Psicoeducativa, 7, 397-427.

Schleppenbach, M., Flevares, L. M., Sims, L. M., \& Perry, M. (2007). Teachers' responses to student mistakes in Chinese and U.S. mathematics classrooms. The Elementary School Journal, 108, 131-147. doi:10.1086/525551 